\title{
The 'wandering' Meckel diverticulum: an unusual scintigraphic finding
}

\author{
Yu-Chin Wu Chia-Hung Kao
}

Received: 26 January 2010 /Revised: 12 February 2010 / Accepted: 26 February 2010 /Published online: 27 March 2010

(C) Springer-Verlag 2010

An 11-year-old boy presented with two episodes of painless hematochezia in a 24-h period and was referred to our nuclear medicine department for a Tc-99m pertechnetate scan (Fig. 1). Sequential abdominal scanning was performed for $105 \mathrm{~min}$ after intravenous administration of radiotracer. The 15-min image showed a focus of radiotracer accumulation in the right upper quadrant just below the liver (Fig. 1, arrow) that increased in intensity and moved downward to the right lower quadrant over time. Laparotomy and pathology showed a Meckel diverticulum lined by gastric mucosa located $50 \mathrm{~cm}$ proximal to the ileocecal valve.

Colitis, polyps, intussusception, volvulus and Meckel diverticulum can cause lower gastrointestinal tract bleeding in children. Moving Meckel diverticula have been reported to be caused by urination and atypical location [1]. This case had a moving diverticulum possibly due to long and mobile mesentery [2]. Movement of the Meckel diverticulum on Tc-99 m pertechnetate scan should not keep one from making the correct diagnosis.

Fig. 1 Sequential scan of abdomen
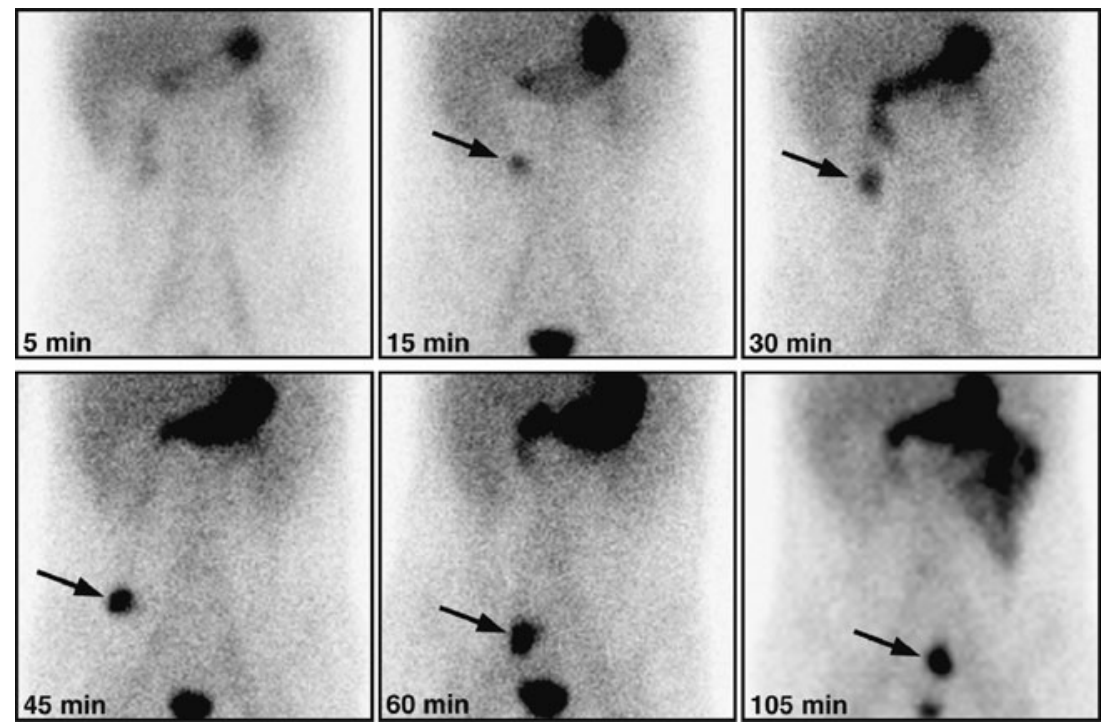

Y.-C. Wu $\cdot$ C.-H. Kao $(\bowtie)$

Department of Nuclear Medicine and PET Center,

China Medical University Hospital, School of Medicine,

China Medical University,

No. 2, Yuh-Der Road,

Taichung 404 Taiwan, China

e-mail: d10040@mail.cmuh.org.tw

\section{References}

1. Hoelzel C, Gillitzer C, Kotzerke J (2007) The floating Meckel. Clin Nucl Med 32:810-811

2. Oglevie SB, Smith DC, Gardiner GA (1989) Angiographic demonstration of bleeding in a unusually located Meckel's diverticulum simulating colonic bleeding. Cardiovasc Intervent Radiol 12:210-212 